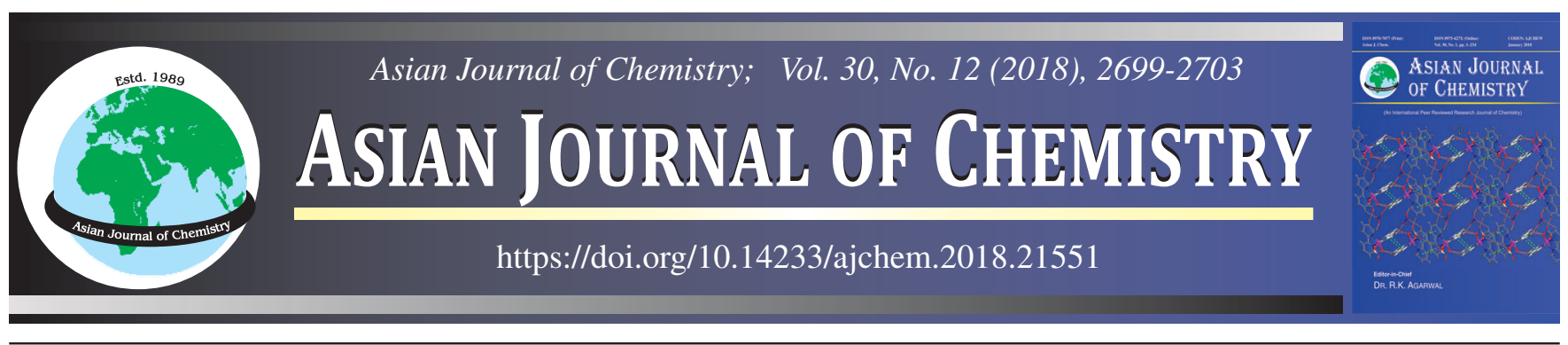

\title{
Optimization of Integration Technology of Field Processing and Processing Crude Drugs of Poria cocos According to Biology Effect and Composition Analyses
}

\begin{abstract}
F.Q. $\mathrm{XU}^{1}$, T.S. $\mathrm{WANG}^{2}$, Y. $\mathrm{FANG}^{1}$, Q. $\mathrm{HUANG}^{1}$, D.L. $\mathrm{WU}^{1, *}$ and C.S. $\mathrm{JIN}^{1, *}$
${ }^{1}$ School of Pharmacy, Anhui University of Chinese Medicine, Hefei City 230012, P.R. China

${ }^{2}$ School of Integrated Traditional and Western Medicine, Anhui University of Chinese Medicine, Hefei city 230012, P.R. China

*Corresponding authors: E-mail: dlwu7375@sina.com; jcs4@ sohu.com

Received: 28 June 2018;

Accepted: 10 August 2018;

Published online: 31 October 2018;

AJC-19134

In this study, the composition analyses along with the diuretic activity and spleen-tonifying effects were adopted to verify the feasibility of integration technology of field processing and processing crude drugs of Poria cocos. The extractions of PCIT and PCTT of Poria cocos administered to rats. The urinary volume and electrolyte excretion $\left(\mathrm{Na}^{+}, \mathrm{K}^{+}, \mathrm{Cl}^{-}\right)$concentrations were measured in the urine of rats and the serum of amylase, D-xylose, gastrin and vasoactive intestinal peptide levels were determined in the spleen deficiency of rats. The PCIT and PCTT could increase the urinary and $\mathrm{Na}^{+}, \mathrm{Cl}^{-}$excretion, the diuretic effect of PCIT was rapider than that of PCTT. The PCIT and PCTT would improve the symptoms of spleen deficiency, the levels of serum amylase, D-xylose, gastrin and vasoactive intestinal peptide tended to be normal in the experiment. The results proved that there was no obvious difference of the substances and the effects on diuretic and spleen-tonifying between the integration technology and traditional technology. The technology of integration of field processing and processing crude drugs is feasible for the production of $P$. cocos.

Keywords: Poria cocos, Crude drugs, HPLC analysis, Diuretic, Spleen-tonifying.

ᄂ
\end{abstract}

\section{INTRODUCTION}

Sclerotia of Poria cocos Wolf (Polyporaceae), is an important Chinese crude drug in prescriptions for its diuretic, tonic and sedative effects since ancient times [1,2]. It has been the first recorded in "Shen Nong Ben Cao Jing" and now mainly cultivated in the warm and sub-tropical regions of Asia, such as China, Japan, Korea and India [3]. Sclerotia of $P$. $\operatorname{cocos}$ is composed of inner parts ("Bai-fuling" in Chinese and "Hoelen" in Japanese) and epidermis parts ("Fulingpi" in Chinese). Previous studies demonstrated that the inner parts [4,5] and epidermis parts [6] are a rich source of triterpenes and polysaccharides. For thousands of years, the inner parts and the epidermis parts of sclerotia had been separately used in prescriptions, the former for diuresis, excreting dampness, invigorating the spleen and tranquilizing the mind, the latter only for dieresis. Pharmacological studies showed that the inner parts of sclerotia of $P$. cocos extract have antitumor, antiinflammatory, antihypertonic stress activities and so on [4,7].
$P$. cocos is one of medicinal herbs with fresh processing, it involves multiple steps from fresh sclerotia of $P$. cocos to slices. Even to this day, the work relies mainly on manual labor in handicraft workshops of cultivated plant. The sclerotia of $P$. cocos has been post-harvest handled with piling up several days for sweating, peeling off epidermis (steaming or not), cutting to slices (sheets, small squares or cube-like), then sundrying or air-drying. The productivity effect and quality of product depend on the weather and traditional experiences [3]. One well-known method to avoid going moldy, sulfurfumigation was used during the process of some decoction pieces and this fungi medicine is no exception basing on habitat and market investigation. Unfortunately, extensive studies revealed that sulfur-fumigation could induce chemical transformation of medicinal herbs [8,9]. Thus, single-factor test, orthography test and comprehensive scoring method were used to optimize the integration technology on primary processing and reprocessing along with external appearance, molding rate and two major characteristic components (triterpenes and

This is an open access journal, and articles are distributed under the terms of the Creative Commons Attribution-NonCommercial 4.0 International (CC BY-NC 4.0) License, which allows others to copy and redistribute the material in any medium or format, remix, transform, and build upon the material, as long as appropriate credit is given and the new creations are licensed under the identical terms. 
polysaccharides) and the superior craft parameters were obtained. As part of ongoing research program for the feasibility of the integration of field processing and processing crude drugs, the diuretic activity and invigorating activity were evaluated in this work.

\section{EXPERIMENTAL}

The reference standards of polyporenic acid C (CFS201601), dehydropachymic acid (CFS201601) and pachymic acid (CFS201502) with purities of $98 \%$ or higher were all purchased from the Wuhan ChemFaces biotechnology Co., Ltd. (Wuhan, China). The commercial diuretic agent furosemide tablet (1611N12, Shanghai Chaohui Pharmaceutical Co. LTD) and Shenling Baizhu pill (1609094, Shandong Kongshengtang Pharmaceutical Co. LTD) was used as a positive control, respectively. Rhubarb decoction (20160701, Bozhou Chengyuan Chinese Herbal Medicine Co., Ltd); methanol and acetonitrile (HPLC grade) were purchased from Tedia (Tedia, USA). Purified water was acquired from a Milli-Q system (Millipore, Bedford, MA, USA). The fresh sclerotia of $P$. cocos were collected in November 2016 at the herbal medicine planting base of Anhui Yatai Natural Plant Technology Co. LTD, A voucher specimen was marked as FL161211. It was identified by Dr. Q.S. Yang (Anhui University of Chinese Medicine, Hefei, China) and deposited at the Laboratory of Processing of Chinese Materia Medica, Anhui University of Chinese Medicine.

Apparatus and chromatographic conditions: Chromatographic analyses were performed on a Shimadzu LC20A system equipped with an equip with SPD-20A detector (Shimadzu, Kyoto, Japan). Chromatographic separation was carried out at $30{ }^{\circ} \mathrm{C}$ on a Phenomenex-C18 column $(250 \mathrm{~mm}$ $\times 4.6 \mathrm{~mm}, 5 \mu \mathrm{m}$, USA). The mobile phase was composed of acetonitrile (A) and aqueous phosphoric acid (0.05\%, v/v) (B). The gradient elution condition was optimized as follows: 0-4 min, 50-55 \% A; 4.0-27.0 min, 55-60\% A; 27.0-35.0 min, 60-65 \% A; 35.0-50.0 min, 65-75\% A; 50.0-60.0 min, $80 \%$ $\mathrm{A}$ and $60.0-65.0 \mathrm{~min}, 80.0-95.0 \% \mathrm{~A}$. The flow rate was 1.0

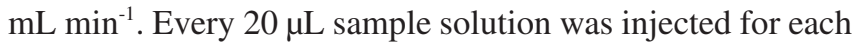
run and the PDA spectra were recorded at $215 \mathrm{~nm}$.

Preparation of reference solutions: The reference compounds polyporenic acid C $(5.12 \mathrm{mg})$, dehydropachymic acid $(7.28 \mathrm{mg})$, pachymic acid $(4.06 \mathrm{mg})$ and dehydrotrametenolic acid $(6.96 \mathrm{mg})$ were accurately weighed and dissolved with methanol in a $10 \mathrm{~mL}$ volumetric flask respectively and stored at $4{ }^{\circ} \mathrm{C}$ as the stock solution. Then, the stock was further diluted with methanol to make six different appropriate concentrations. The working solutions were filtered through a $0.22 \mu \mathrm{m}$ membrane prior to injection.

Preparation of sample solution: The slices of integration technology of field processing and processing crude drugs (PCIT): The fresh of sclerotia of $P$. cocos, sweating 3 days, steaming $90 \mathrm{~min}$, peeling off epidermis by hand, cutting into slices $(0.8 \mathrm{~cm} \times 0.8 \mathrm{~cm} \times 0.8 \mathrm{~cm})$ with machines, air-dried with a cool for two days, then drying with steam $16 \mathrm{~h}$ at $50{ }^{\circ} \mathrm{C}$ in the drying room; The slices of tradition technology (PCTT): The fresh of sclerotia of $P$. cocos, sweating 3 days, peeling off epidermis by hand, cutting into slices $(0.8 \mathrm{~cm} \times 0.8 \mathrm{~cm} \times 0.8$ $\mathrm{cm}$ ) by hand, sun-dried directly for 3 days. Then, the powder of the slice of $P \cdot \operatorname{cocos}\left(60{ }^{\circ} \mathrm{C}\right.$ dried, 80 mesh), was precisly weighed $(2.000 \mathrm{~g})$ and transferred into a conical flask with stopper. Then it was extracted with methanol $(20 \mathrm{~mL})$ in an ultrasonic bath for $30 \mathrm{~min}$ at $45^{\circ} \mathrm{C}(40 \mathrm{KHz}, 400 \mathrm{~W})$. Additional methanol was added to make up the lost. The supernatant was filtered through a $0.22 \mu \mathrm{m}$ membrane prior to injection.

Male SD rats (weighing $200 \pm 20 \mathrm{~g}$, SPF) were purchased from Anhui Experimental Animal Center of China [license number SCXK (Wan) 2011-002]. All animals were housed in plastic cages at $20-25{ }^{\circ} \mathrm{C}$ and constant humidity (40-70\%) under a $12 \mathrm{~h}$ light-dark cycle at least 3 days before experimentation with free access to standard laboratory food and water adlibitum in SPF grade laboratory. All experiments and procedures were carried out according to the Regulations of Experimental Animal Administration issued by the State Committee of Science and Technology of China and the animal study was approved by the Animal Ethics Committee of Anhui Province. Each experimental group consisted of 10 animals.

Extracts preparation: The PCIT (decoction pieces of integration technology of field processing and processing crude drugs, $5.0 \mathrm{Kg})$ were extracted with water $(40 \mathrm{~L} \times 2)$ under reflux $(2 \mathrm{~h})$. The filtrate was vapourized at $80{ }^{\circ} \mathrm{C}$ to yield a brown crude extract, which dried in a vacuum oven at $60{ }^{\circ} \mathrm{C}$ for $24 \mathrm{~h}$. The PCTT (decoction pieces of traditional technology) were prepared with the same processing. The yield of the PCIT was $2.14 \%$ (w/w) and PCTT was $2.18 \%$ (w/w).

Diuretic assay: The diuretic activity was performed according to the method described by Zhao et al. [10] with slight modifications. Briefly, the eligible animals were randomized into control and experimental groups. The tested substances were diluted with distilled water to the required concentrations. Animals in the normal group were administered with distilled water. The solutions of the tested substance via ig (intragastric administered) to the rat at a dosage of required concentration $(1 \mathrm{~mL} / 100 \mathrm{~g}$, body weigh) once a day for 7 days. After the last treatment, rats were deprived of food but not water for $12 \mathrm{~h}$. Each rat was given distilled water at an oral dose of $2.5 \%$ body weight to impose a uniform water load and individually placed in a metabolism cage. The cumulative urine output was determined at designated time. The electrolyte $\left(\mathrm{Na}^{+}, \mathrm{K}^{+}, \mathrm{Cl}^{-}\right)$ concentrations and $\mathrm{pH}$ were determined in the $24 \mathrm{~h}$ urine samples from the rats.

Spleen-tonifying assay: The spleen-tonifying activity was performed according to the method described by Deng [11] with slight modifications. In brief, the animals were treated to reproduce the spleen-deficiency syndrome model by the combination method, including administrated decoction of Rheum palmatum L. (1 mL/100 g, body weight, a.m.), the loaded swimming (10\% body weight, p.m.) and starvation except control group, once a day for three weeks. During this period, the solutions of the tested substances by intragastric to the rat at a dosage of the required concentration, animals of the normal group and model group were administered with distilled $\mathrm{H}_{2} \mathrm{O}$. During the period the daily state of rats, including water, food, activity and weight was observed. After the last treatment, rats were deprived of food but not water for $12 \mathrm{~h}$. The serum amylase, D-xylose, gastrin and vasoactive intestinal peptide were determined according to the kit methods [12]. 
Data analysis: All results are expressed as mean \pm SD. Normal distributions data were analyzed by LDS-t-test and skew distribution data were analyzed by rank-sum test. The criterion for statistical significance was $\mathrm{P}<0.05$. All statistic analyses were carried out by using SPSS for Windows (SPSS Inc. 23.0 version).

\section{RESULTS AND DISCUSSION}

Chromatographic conditions: The chromatographic conditions were chosen on some experiment' results, including mobile phase compositions ( $\mathrm{MeOH}-\mathrm{H}_{2} \mathrm{O}, \mathrm{CH}_{3} \mathrm{CN}-\mathrm{H}_{2} \mathrm{O}$ with/ without acetic acid or phosphoric acid), $\mathrm{C} 18$ columns (Aglient, Waters and Phenomenex), the column temperatures $\left(20^{\circ} \mathrm{C}\right.$, $25^{\circ} \mathrm{C}$ and $\left.30^{\circ} \mathrm{C}\right)$ and the detective wavelength $(254 \mathrm{~nm}, 242$ $\mathrm{nm}$ and $215 \mathrm{~nm}$ ). As a result, the sample was chromatographed on a Phenomenex C18 column $(250 \mathrm{~mm} \times 4.6 \mathrm{~mm}, 5 \mu \mathrm{m})$ and eluted with acetonitrile-aqueous phosphoric acid $(0.05 \%, \mathrm{v} / \mathrm{v})$ gradient, to afford a best separation, at $30{ }^{\circ} \mathrm{C}$ with a flow rate of $1.0 \mathrm{~mL} / \mathrm{min}$.

Calibration curves and method validation: The calibration curves were constructed by the peak area (y) versus the quality (x) of each reference compound with 6 different concentrations in twice. The regression equations (lineranges) were calculated as following: $\mathrm{y}=51970 \mathrm{x}+802.9(0.0256-0.2304$ $\mu \mathrm{g}$, polyporenic acid C), $\mathrm{y}=40829 \mathrm{x}-1428(0.0728-0.3740$ $\mu \mathrm{g}$, dehydropachymic acid), $\mathrm{y}=53931 \mathrm{x}+26886(0.0532-$ $2.03 \mu \mathrm{g}$, pachymic acid) and $\mathrm{y}=76985 \mathrm{x}+1661(0.0348-0.348$ $\mu \mathrm{g}$, dehydrotrametenolic acid). All the marker substances showed good linearity $\left(r^{2} \geq 0.999\right)$. The system applicability test was according to the Chinese Pharmacopoeia [13]. The results of the precision, stability, repeatability and accuracy test demonstrated that the established HPLC method is good enough for simultaneous quantification of four major components in P. cocos.

Quantitative analysis: The contents of three compounds in P. cocos samples analyzed were listed in Table-1. polyporenic acid $\mathrm{C}$, dehydropachymic acid and pachymic acid, the main bioactive substances in $P$. cocos which were selected for the content detection target in this study $[14,15]$. The results showed that the contents of three triterpenes were different although the characteristic chromatograms of PCTT and PCIT were very similar (Table-1 and SI). Overall, the contents of substances of the sample of PCIT were higher than those of PCTT. Therefore, in terms of effective components, the technology of integration of field processing and processing crude drugs was superior over the traditional technology.

\begin{tabular}{cccc}
\multicolumn{5}{c}{ TABLE-1 } \\
CONTENTS OF THE THREE COMPONENTS \\
IN P. cocos $(\mathrm{mg} / \mathrm{g} \pm$ S.D., $\mathrm{n}=2)$ \\
\hline \multirow{2}{*}{ Samples } & Polyporenic & Dehydropachymic & Pachymic \\
& acid C $(\mathrm{mg} / \mathrm{g})$ & acid $(\mathrm{mg} / \mathrm{g})$ & acid $(\mathrm{mg} / \mathrm{g})$ \\
\hline PCIT & 0.26 & 0.41 & 0.98 \\
PCTT & 0.21 & 0.31 & 0.76 \\
\hline
\end{tabular}

\section{Effect of PCTT and PCIT on urinary volume and electrolyte excretion in rats}

Urinary volume excretion: After treatment for 1 week, the result of urinary volume excretion of PCTT $(5.0 \mathrm{~g} / \mathrm{kg})$ and PCIT $(1.25,2.5$ and $5.0 \mathrm{~g} / \mathrm{kg})$ are shown in Fig. 1. The data demonstrated that all the dose of the PCTT and PCIT significantly would increase the urinary output in $24 \mathrm{~h}$ compared with the control group $(\mathrm{P}<0.05)$. The lower $(1.25 \mathrm{~g} / \mathrm{kg})$ dose of the PCIT for urine output became significantly higher than that of the control rats in $6 \mathrm{~h}$. The effect of the reference diuretic drug, furosemide was also rapider (in $6 \mathrm{~h}$ ) and higher than those of the PCTT and PCIT. The result showed that all the doses of the $P$. cocos exhibited a diuretic effect in $24 \mathrm{~h}$ and PCIT would take effect more quickly.

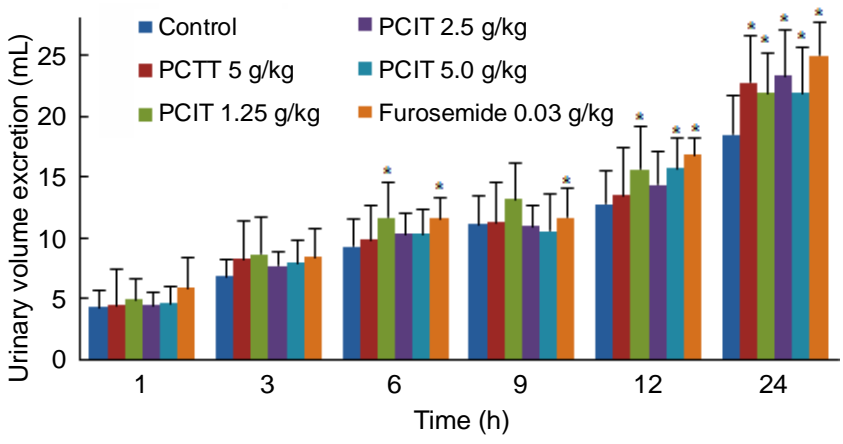

Fig. 1. Effects of different process of P. cocos pieces and furosemide on urine output of the treated rats (the values are the mean $\pm \mathrm{SD}, * \mathrm{P}<$ $0.05 v s$. control group)

Electrolyte excretion: The electrolyte excretion of combined urine in total $24 \mathrm{~h}$ after the oral administration of PCTT and PCIT were shown in Table-2. Compared with control group, the extracts of $P$. cocos pieces would increase $\mathrm{Na}^{+}$and $\mathrm{Cl}^{-}$excretion, but only the lower $(1.25 \mathrm{~g} / \mathrm{kg})$ dose of PCI2T arrived at statistically significant $(\mathrm{p}<0.5)$. Compared PCIT groups with PCTT group, the electrolyte excretions of $\mathrm{Na}^{+}$, $\mathrm{K}^{+}$and $\mathrm{Cl}^{-}$exhibited non-significant. The $\mathrm{pH}$ values of the urine treated with the dose $(5.0 \mathrm{~g} / \mathrm{kg})$ of PCTT and PCIT were higher than that of the control group but non-significant. The

TABLE-2

EFFECTS OF DIFFERENT PROCESS OF $P$. cocos SLICES AND FUROSEMIDE ON ELECTROLYTES EXCRETED IN COMBINED URINE IN TOTAL $24 \mathrm{~h}$

\begin{tabular}{ccccccc}
\hline Group & Dose $(\mathrm{g} / \mathrm{kg})$ & $\mathrm{pH}$ & Density & $\mathrm{K}^{+}(\mathrm{mmol} / \mathrm{mL})$ & $\mathrm{Na}^{+}(\mathrm{mmol} / \mathrm{mL})$ & $\mathrm{Cl}^{-}\left(\mathrm{mmol} / \mathrm{mL}^{2}\right)$ \\
\hline Control & - & $7.35 \pm 0.88$ & $1.01 \pm 0.01$ & $66.00 \pm 15.66$ & $14.40 \pm 4.19$ & $18.00 \pm 5.17$ \\
PCTT & 5.00 & $8.10 \pm 0.81$ & $1.01 \pm 0.01$ & $68.60 \pm 18.44$ & $31.16 \pm 6.24$ & $40.38 \pm 15.31$ \\
PCIT & 1.25 & $7.10 \pm 0.91$ & $1.01 \pm 0.01$ & $68.40 \pm 28.24$ & $29.76 \pm 4.89^{*}$ & $36.28 \pm 5.17^{*}$ \\
PCIT & 2.50 & $7.15 \pm 0.91$ & $1.02 \pm 0.01$ & $59.40 \pm 9.96$ & $27.98 \pm 5.27$ & $33.20 \pm 6.12$ \\
PCIT & 5.00 & $8.35 \pm 0.91$ & $1.01 \pm 0.29$ & $55.00 \pm 21.98$ & $33.28 \pm 12.44$ & $33.24 \pm 13.49$ \\
Furosemide & 0.03 & $6.94 \pm 0.88$ & $1.01 \pm 0.01$ & $76.00 \pm 16.07$ & $50.96 \pm 12.07^{* \#}$ & $57.78 \pm 12.01^{* \#}$ \\
\hline
\end{tabular}

Note: compared with the control group * $\mathrm{p}<0.05$; compared with the PCTT preparation ${ }^{*} \mathrm{p}<0.05$. 
density of urine was equal to the control group. Thus these data demonstrated an increase the output of $\mathrm{Na}^{+}$excretion but not $\mathrm{K}^{+}$excretion by all the dose of PCTT groups and PCIT group, which is an effect of the sodium loss and potassium retention.

\section{Effect of PCTT and PCIT on spleen deficiency of rats}

Changes of signs: The control group rats have white smooth hair and without problem in feeding, spirits, excretory functions and activity. After one week treatment, the expected state of the model group rats had been observed: bad appetite, lassitude, slow response, weight loss, inactiveness and grouping; two weeks later, those demonstrated all the above signs, which are similar to the symptoms of traditional Chinese medicine (TCM) spleen deficiency pattern in human [11]. And treated groups' symptoms of spleen deficiency get better than model group.

Changes of serum amylase and D-xylose: Table-3 shows the changes of the serum amylase and D-xylose in spleen deficiency model rats. The levels of serum amylase and D-xylose in model group were lower than those in normal group without significance $(p>0.05)$. Compared with the model group, the levers of serum amylase and D-xylose were higher than those in the treated groups and three doses of PCIT and Shenling Baizhu pill reach statistically significant $(\mathrm{p}<0.05)$. The results suggested that the PCTT, PCIT and Shenling Baizhu pill can increase the serum amylase activity and content of serum Dxylose of spleen deficiency model rats. As far as concerned, integration technology of field processing has an advantage effect over processing crude drugs of $P$. cocos on spleentonifying activity, although without significant.

\begin{tabular}{|c|c|c|c|}
\hline \multicolumn{4}{|c|}{$\begin{array}{c}\text { TABLE-3 } \\
\text { EFFECTS OF DIFFERENT PROCESSING TECHNIQUES } \\
P . \operatorname{cocos} \text { ON SERUM AMYLASE AND D-XYLOSE IN } \\
\text { SPLEEN DEFICIENCY MODEL RATS }\end{array}$} \\
\hline Group & Dose $(\mathrm{g} / \mathrm{kg})$ & Serum amylase $(\mathrm{u} / \mathrm{dl})$ & $\begin{array}{l}\text { D-xylose } \\
(\mathrm{mmol} / \mathrm{L})\end{array}$ \\
\hline Normal & - & $3686.486 \pm 1336.203$ & $1.829 \pm 0.438$ \\
\hline Model & - & $2794.499 \pm 1023.106$ & $1.381 \pm 0.446^{*}$ \\
\hline PCTT & 5.00 & $5218.018 \pm 1873.088$ & $1.679 \pm 0.383$ \\
\hline PCIT & 1.25 & $4209.009 \pm 1120.638$ & $1.949 \pm 0.416^{\#}$ \\
\hline PCIT & 2.50 & $3070.270 \pm 1091.944$ & $1.957 \pm 0.392^{\#}$ \\
\hline PCIT & 5.00 & $3009.009 \pm 1830.108$ & $1.845 \pm 0.429^{\#}$ \\
\hline $\begin{array}{l}\text { Shenling } \\
\text { Baizhu pill }\end{array}$ & 0.30 & $3409.009 \pm 1884.102$ & $1.842 \pm 0.441^{\#}$ \\
\hline
\end{tabular}

Changes on gastrin and vasoactive intestinal peptide in serum: Spleen-stomach theory is a comprehensive one in the traditional Chinese medicine. In recent years, some studies reported that spleen-dificiency syndrome was closely related to gastrointestinal hormones, the serum gastrin level in the patients with spleen-dificiency was lower, while vasoactive intestinal peptide level was significantly higher than those of non-spleen deficiency [16-18]. In this study, Table-4 shows the changes on the serum gastrin and vasoactive intestinal peptide. The results demonstrated that there was the lower level of gastrin in the rats of model group $(\mathrm{p}<0.05)$, the extracts of P. cocos (PCTT and PCIT) and Shenling Baizhu pill could increase the level of gastrin in serum for the spleen deficiency rats, but shown no statistically significant with normal group except the dose $(1.25 \mathrm{~g} / \mathrm{kg})$ of PCIT group. Moreover, the serum gastrin lever of $5.0 \mathrm{~g} / \mathrm{kg}$ dose of PCIT group significantly increased compared with those in model group $(p<0.05)$. While, the serum vasoactive intestinal peptide of spleen deficiency rats could be increased to normal by three doses of PCIT and Shenling Baizhu pill ( $p>0.05)$. Further analysis of the results revealed that the $5.0 \mathrm{~g} / \mathrm{kg}$ and $1.25 \mathrm{~g} / \mathrm{kg}$ of PCIT would reserve the changes of serum vasoactive intestinal peptide of spleen deficiency rats $(\mathrm{p}<0.05)$. Based on the above data, PCIT and PCTT could restore the distorted neuroendocrinoimmune responses, which could be part of mechanism in the treatment of the patients with traditional Chinese medicine spleen deficiency pattern. The restorative effect of the integrated process was better than that of the traditional technology.

TABLE-4

EFFECTS OF DIFFERENT PROCESSING TECHNIQUES $P$. cocos ON SERUM GASTRIN AND VASOACTIVE INTESTINAL PEPTIDE IN SPLEEN DEFICIENCY MODEL RATS

\begin{tabular}{cccc}
\hline Group & $\begin{array}{c}\text { Dose } \\
(\mathrm{g} / \mathrm{kg})\end{array}$ & $\begin{array}{c}\text { Serum gastrin } \\
(\mathrm{pg} / \mathrm{mL})\end{array}$ & $\begin{array}{c}\text { Serum vasoactive } \\
\text { intestinal peptide } \\
(\mathrm{pg} / \mathrm{mL})\end{array}$ \\
\hline Control & - & $324.23 \pm 38.43$ & $128.81 \pm 19.63$ \\
Model & - & $252.02 \pm 39.28^{*}$ & $171.85 \pm 27.56^{*}$ \\
PCTT & 5.00 & $296.21 \pm 54.59$ & $153.41 \pm 43.56^{*}$ \\
PCIT & 1.25 & $262.39 \pm 42.77^{*}$ & $136.88 \pm 33.49^{\#}$ \\
PCIT & 2.50 & $282.32 \pm 31.45$ & $149.47 \pm 32.69$ \\
PCIT & 5.00 & $299.52 \pm 36.82^{\#}$ & $140.53 \pm 22.58^{\#}$ \\
Shenling & 0.30 & $292.46 \pm 51.70$ & $136.94 \pm 38.89^{\#}$ \\
Baizhu pill & & &
\end{tabular}

Note: Compared with the control group * $\mathrm{p}<0.05$; compared with the model group ${ }^{\#} \mathrm{p}<0.05$.

\section{Conclusion}

In conclusion, this work represent that there was no obvious difference of the substances and the effects on diuretic and spleen-tonifying between the integration technology and traditional technology. The technology of integration of field processing and processing crude drugs is feasible for the production of $P$. cocos.

\section{ACKNOWLEDGEMENTS}

This work was supported by Special Fund for Scientific Research of Traditional Chinese Medicine Industry (20150700218) and the Open Fund of State Key Laboratory of Tea Plant Biology and Utilization (SKLTOF20160109). The authors thank the Anhui Innovative Team from Colleges for Scientific Research's Platform-The Innovative Team in Researching the Key Technologies concerning the Integration of Processing Chinese Medicine Decoction Pieces in Producing Area.

\section{CONFLICT OF INTEREST}

The authors declare that there is no conflict of interests regarding the publication of this article.

\section{REFERENCES}

1. Z.L. Wu, H. Ren, W.Y. Lai, S. Lin, R.Y. Jiang, T.C. Ye, Q.B. Shen, Q.C. Zeng and D.L. Xu, J. Ethnopharmacol., 155, 563 (2014); https://doi.org/10.1016/j.jep.2014.05.054. 
2. N. Zhao, W.D. Zhang, Y.M. Guo, H.W. Jia, Q.L. Zha, Z.L. Liu, S.J. Xu and A.P. Lu, J. Ethnopharmacol., 133, 454 (2011); https://doi.org/10.1016/j.jep.2010.10.016.

3. T.T. Xu, C.S. Jin, D.L. Wu, W. Zhang and J. Wang, J. Anhui TCM Coll., 32, 77 (2013).

4. S.R. Lee, S. Lee, E. Moon, H.J. Park, H.B. Park and K.H. Kim, Bioorg. Chem., 70, 94 (2017);

https://doi.org/10.1016/j.bioorg.2016.11.012.

5. J.L. Ríos, I. Andújar, M.C. Recio and R.M. Giner, J. Nat. Prod., 75, 2016 (2012); https://doi.org/10.1021/np300412h.

6. T. Akihisa, E. Uchiyama, T. Kikuchi, H. Tokuda, T. Suzuki and Y. Kimura, J. Nat. Prod., 72, 1786 (2009); https://doi.org/10.1021/np9003239.

7. Y.Z. Wang, J. Zhang, Y.L. Zhao, T. Li, T. Shen, J.Q. Li, W.Y. Li and H.G. Liu, J. Ethnopharmacol., 147, 265 (2013); https://doi.org/10.1016/j.jep.2013.03.027.

8. P.Y. Hayes, R. Lehmann, K. Penman, W. Kitching and J.J. De Voss, Tetrahedron Lett., 46, 2615 (2005); https://doi.org/10.1016/i.tetlet.2005.02.082.

9. S.L. Li, H. Shen, L.Y. Zhu, J. Xu, X.B. Jia, H.M. Zhang, G. Lin, H. Cai, B.C. Cai, S.L. Chen and H.X. Xu, J. Chromatogr. A, 1231, 31 (2012); https://doi.org/10.1016/j.chroma.2012.01.083.
10. Y.-Y. Zhao, Y.-L. Feng, X. Du, Z.-H. Xi, X.-L. Cheng and F. Wei, J. Ethnopharmacol., 144, 775 (2012); https://doi.org/10.1016/j.jep.2012.09.033.

11. C.Y. Deng, Ph.D. Dissertation, The study of Pharmacodynamics of Buzhong Yiqi Decoction with its compatibility Mechanism, Guangzhou Univeristy of Chinese Medicines, P.R. China (2012).

12. Y. Lei, Z.Y. Huo, L.S. Liu, F. Zhang and Q. Yang, Pharmacol. Clin. Chin. Mater. Med., 28, 5 (2012).

13. Chinese Pharmaceutical Association, Chinese Pharmacopoeia, Chinese Medical Science and Technology Press: Beijing, pp. 240-241(2015).

14. Y.C. Huang, W.L. Chang, S.F. Huang, C.Y. Lin, H.C. Lin and T.C. Chang, Eur. J. Pharmacol., 648, 39 (2010); https://doi.org/10.1016/j.ejphar.2010.08.021.

15. S. Lee, D. Lee, S.O. Lee, J.Y. Ryu, S.Z. Choi, K.S. Kang and K.H. Kim, J. Funct. Foods, 32, 27 (2017); https://doi.org/10.1016/j.jff.2017.02.012.

16. L.S. Li, R.Y. Qu, W. Wang and H. Guo, World J. Gastroenterol., 9, 553 (2003); https://doi.org/10.3748/wjg.v9.i3.553.

17. S.A. Watson, A.M. Grabowska, M. El-Zaatari and A. Takhar, Nat. Rev. Cancer, 6, 936 (2006); https://doi.org/10.1038/nrc2014.

18. Y.P. Song, H.F. Chen, Y.X. Hu, S.S. Tan, X.Q. Luo and W.L. Yang, Pharmacol. Clin. Chin. Mater. Med., 33, 79 (2017). 